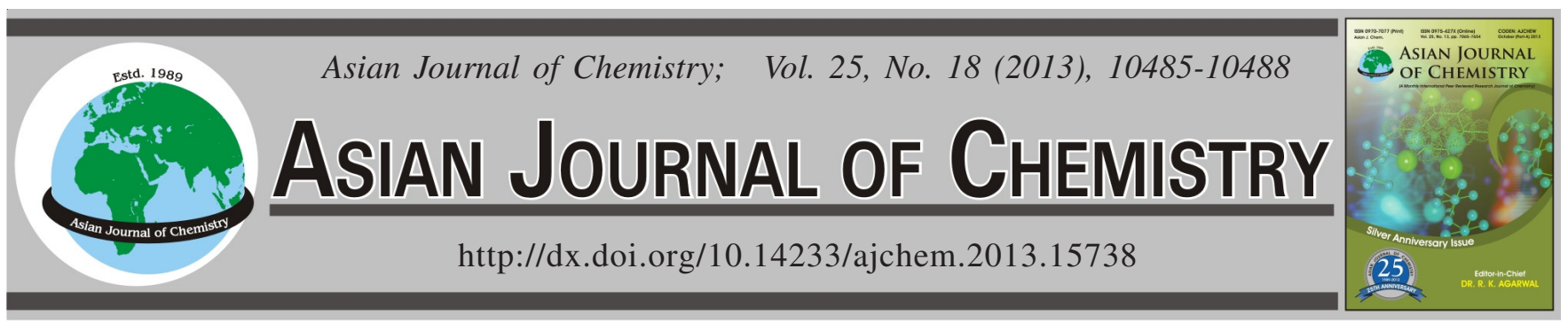

\title{
Adsorption Behaviours of Sorbic Acid onto Polymeric Adsorbent Modified with 2-Carboxybenzoyl Group
}

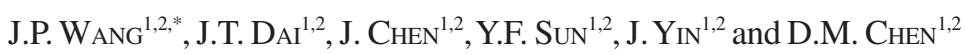

\begin{abstract}
${ }^{1}$ Jiangsu Provincial Key Laboratory of Coastal Wetland Bioresources and Environmental Protection; Department of Chemistry, Yancheng Teachers University, Xiwang Road, Yancheng 224051, Jiangsu Province, P.R. China.

${ }^{2}$ Institute of Applied Chemistry and Environmental Engineering, Department of Chemistry, Yancheng Teachers University, Yancheng 224051, Jiangsu Province, P.R. China
\end{abstract}

*Corresponding author: Tel/Fax: +86515 88233188; E-mail: wjp-22@163.com

(Received: 7 May 2013;

Accepted: 22 November 2013)

AJC-14432

\begin{abstract}
In the present study, a hypercrosslinked polymeric adsorbent (ZH-01) was employed to remove sorbic acid. The study focuses on the static equilibrium adsorption behaviours and the adsorption thermodynamics. Freundlich and Langmuir model give perfect fitting to the isotherm data. The adsorbing capacities for sorbic acid on ZH-01 is higher than on Amberlite XAD-4 within the temperature range 288-318 $\mathrm{K}$, which is contributed to microporous structure and the polar groups on the network of ZH-01 resin. The changes of enthalpy, free energy, entropy were indicative of an exothermic, a spontaneous and disorder decreasing process. The data of the kinetics were fit for the first-order equation. The results showed that the hypercrosslinked polymeric adsorbent (ZH-01) was better than the Amberlite XAD-4 for removing the sorbic acid in aqueous solutions.
\end{abstract}

Key Words: Hypercrosslinked resins, Sorbic acid, Adsorption.

ᄂ - - - - - - - - - - - - - - - - - - - - - - - -

\section{INTRODUCTION}

Sorbic acid, as one of the most important preservative, is widely used for the manufacture of food. As a result, more and more sorbic acid wastewater has been introduced into water bodies. For their high toxicity, the efficient removal of these organic compounds from water has draw significant concern ${ }^{1}$.

Presently, various methods of wastewater treatment have been developed such as catalytic oxidation, liquid membrane separation, biological degradation and adsorption ${ }^{2}$. Due to the high concentration ability of typical adsorbents, adsorption is proved to be one of the most attractive and effective techniques for purification and separation in wastewater treatment ${ }^{3}$.

The present work aimed at investigation of the adsorption behaviours of sobic acid from their aqueous solutions onto $\mathrm{ZH}-01$ adsorbent containing 2-carboxybenzoyl group. In comparison with Amberlite XAD-4, ZH-01 has higher adsorption capacity for sorbic acid, because it is high micropore area and the presence of 2-carboxybenzoyl functional group.

\section{EXPERIMENTAL}

Acetone, ethanol, zinc chloride, 2-chloromethane, hydrochloric acid, nitrobenzene, phthalic anhydride, sorbic acid were used in this study. All these chemicals are of analytical grade and were purchased from Shanghai Chemical Reagent
Plant (Shanghai, China). Styrene and divinylbenzene (purity: $50.4 \%$ ) were purchased from Dongda Chemical Co. Ltd, (Shandong province, China). Chloromethyl methylether was obtained from Langfang Chemical Co. Ltd. (Hebei province, China). The spherical Amberlite XAD-4 resin was purchased from Rohm and Haas Company (Philadelphia, USA). Sorbic acid used in this study was analytical grade reagents of $99.5 \%$ purity (Shanghai Chemical Reagent Plant, China). The reagent was used to prepare the stock solution with a concentration of $500 \mathrm{mg} / \mathrm{L}$, which was kept in sealed ground-glass-stoppered brown bottles and stored in a refrigerator at $4{ }^{\circ} \mathrm{C}$.

Synthesis of ZH-01 resin: ZH-01 was synthesized according to literature ${ }^{4}$. In a $500 \mathrm{~mL}$ round-bottomed flask, $50 \mathrm{~g}$ of chloromethylated poly(styrene-divinylbenzene) beads (chlorine content $19.5 \%$ ) were swollen in $600 \mathrm{~mL}$ nitrobenzene. Under mechanical stirring, $5 \mathrm{~g}$ of zinc chloride were added slowly at room temperature. The mixture was further stirred for $8 \mathrm{~h}$ at $408 \mathrm{~K}$. After cooled, $10 \mathrm{~g}$ phthalic anhydride were added to the above mixture at $383 \mathrm{~K}$ and stirred for another $15 \mathrm{~h}$.

Finally, the mixture was poured into an acetone bath, which contained $1 \%$ hydrochloric acid. The filtered polymers were extracted with ethanol for $8 \mathrm{~h}$ in a Soxhlet apparatus and dried under vacuum at $333 \mathrm{~K}$ for $8 \mathrm{~h}$. The properties of ZH-01 and XAD-4 resins are given in Table-1. 
TABLE-1

TYPICAL PROPERTY OF THE POLYMERIC RESINS

\begin{tabular}{lcc}
\hline \multicolumn{1}{c}{ Property } & XAD-4 & ZH-01 \\
\hline Polarity & Non-polar & Moderate polar \\
Specific surface $\operatorname{area}\left(\mathrm{m}^{2} / \mathrm{g}\right)$ & 880 & 1118 \\
Average diameter $(\mathrm{nm})$ & 5.8 & 1.2 \\
Micropore area $\left(\mathrm{m}^{2} / \mathrm{g}\right)$ & 3 & 686 \\
Average particle size $(\mathrm{mm})$ & 0.5 & 0.5 \\
Porosity $(\mathrm{mL} / \mathrm{g})$ & 1.0 & 0.69 \\
Residual chlorine content $(\%)$ & 0 & 2.8 \\
Colour & White & Brown \\
\hline
\end{tabular}

Analytical method: An Agilent gas chromatograph equipped with a HP-5 column $(30 \mathrm{~m} \times 0.35 \mathrm{~mm} \times 0.25 \mu \mathrm{m})$ was used to separate and determine the level of sorbic acid in water samples. Of course, all samples were filtered with a $0.45 \mu \mathrm{m}$ membrane and sorbic acid was extracted with 2chloromethane for analysis. The oven temperature was programmed as follows: $80^{\circ} \mathrm{C}$ for $1 \mathrm{~min}$, increasing to $150^{\circ} \mathrm{C}$ at $15^{\circ} \mathrm{C} / \mathrm{min}$ and hold for $1 \mathrm{~min}$, then increasing to $250^{\circ} \mathrm{C}$ at $10{ }^{\circ} \mathrm{C} / \mathrm{min}$, hold for $1 \mathrm{~min}$. The injector and detector temperatures were kept at $250{ }^{\circ} \mathrm{C}$ and $280^{\circ} \mathrm{C}$, respectively. Nitrogen $(99.999 \%)$ was used as carrier gas and make-up gas.

Adsorption experiments: Equilibrium adsorption of sorbic acid was performed at three difference temperatures: $288 \mathrm{~K}, 303 \mathrm{~K}$ and $318 \mathrm{~K}$. Dry ZH-01 resin (0.1 g) was weighed accurately and introduced into a $250 \mathrm{~mL}$ conical flask directly, while the XAD-4 resin should be wetted in $0.5 \mathrm{~mL}$ methanol and rinsed with deionized water for more than three times before use. Then, $100 \mathrm{~mL}$ aqueous solution of the adsorbates of certain concentration $\left(\mathrm{C}_{0}, \mathrm{mg} / \mathrm{L}\right)$ ranging from 80 to 400 was added to each flask. The flasks were completely sealed and shaken in a ZD-880D model incubator shaker (Taichang, bolate Scientific Co. Inc.) at a presettled temperature under $130 \mathrm{rpm}$ until equilibrium reached. The concentration $\left(\mathrm{C}_{\mathrm{e}}\right.$, $\mathrm{mg} / \mathrm{L}$ ) of the residual aqueous phase was determined using the method above. Thus, the concentration of the adsorbentphase solute, $\mathrm{Q}_{\mathrm{e}}(\mathrm{mmol} / \mathrm{g})$, is calculated as below:

$$
\mathrm{Q}_{\mathrm{e}}=\mathrm{V}_{1}\left(\mathrm{C}_{0}-\mathrm{C}_{\mathrm{e}}\right) / \mathrm{M} \mathrm{W}
$$

where $\mathrm{V}_{1}$ is the volumn of solution $(\mathrm{L}), \mathrm{W}$ is the weight of dry resin $(\mathrm{g})$ and $\mathrm{M}$ is the molecular weight of corresponding adsorbate.

\section{RESULTS AND DISCUSSION}

Static equilibrium adsorption: Equilibrium data concerning the adsorption of the sorbic acid from aqueous solutions onto the two adsorbents were shown in Fig. 1 and 2. It is well known that increasing temperature was disadvantageous for a physical adsorption process. The equilibrium adsorption capacities of sorbic acid on $\mathrm{ZH}-01$ and Amberlite $\mathrm{XAD}-4$ decrease with the increase of temperature, which are the chracteristic of physical adsorption process. The adsorbing capacities for sorbic acid on the ZH-01 is significantly higher than that on Amberlite XAD-4, which may be contributed to its high micropore area and 2-carboxybenzoyl functional groups on the networks.

Freundlich model was used to fit the equilibrium adsorption data. The model was rearranged and expressed as below. Freundlich equation:

$$
\ln \mathrm{Q}_{\mathrm{e}}=\ln \mathrm{K}_{\mathrm{F}}+1 / \mathrm{n} \ln \mathrm{c}_{\mathrm{e}}
$$

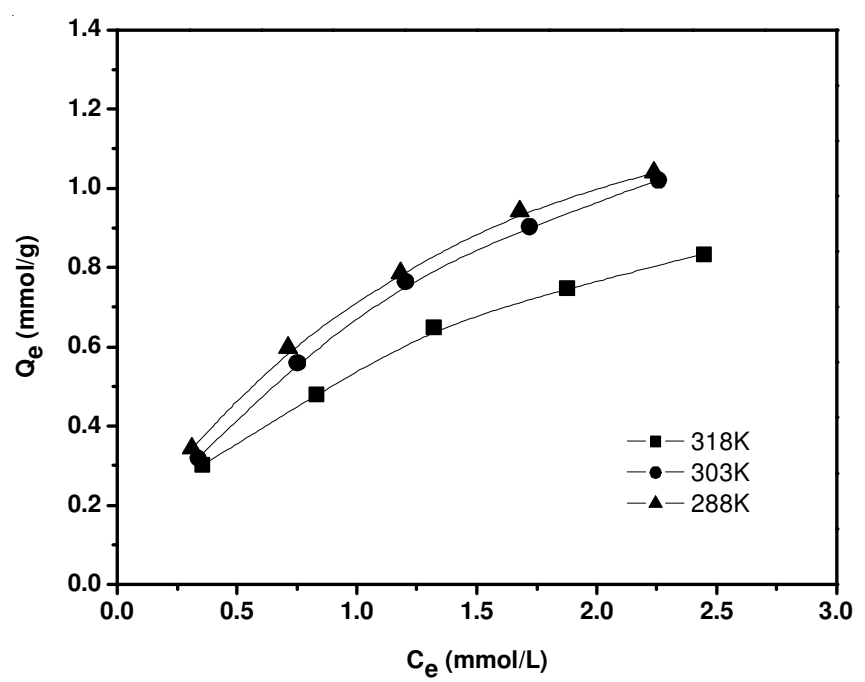

Fig. 1. Equilibrium adsorption isotherms for sorbic acid on ZH-01 at different temperature

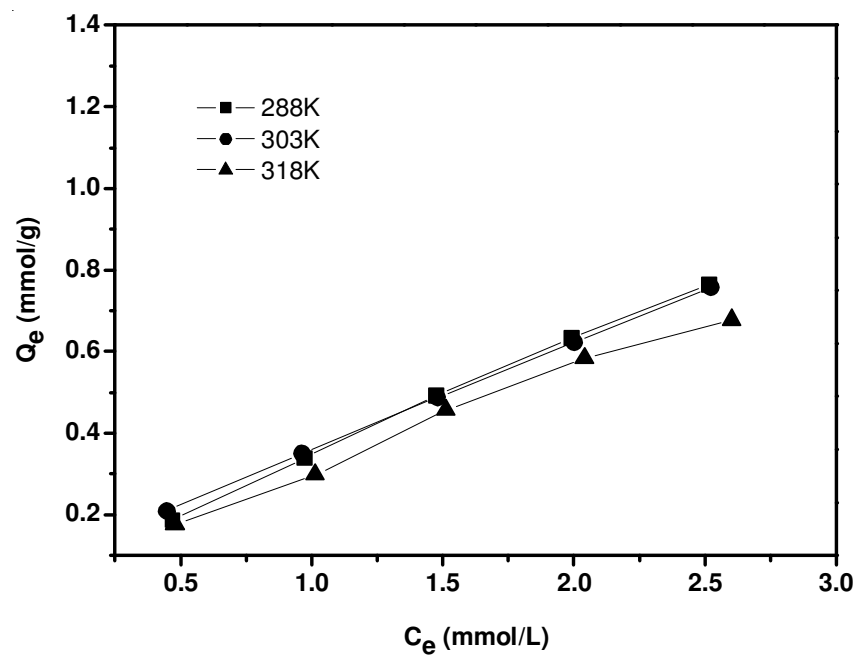

Fig. 2. Equilibrium adsorption isotherms for sorbic acid on XAD-4 at different temperature

where $\mathrm{Q}_{\mathrm{e}}$ is the equilibrium adsorption capacity ( $\left.\mathrm{mmol} / \mathrm{g}\right), \mathrm{C}_{\mathrm{e}}$ the equilibrium concentration ( $\mathrm{mmol} / \mathrm{L}$ ), $\mathrm{K}_{\mathrm{F}}$ and $\mathrm{n}$ the characteristic constants. The evaluated constants for the isotherms are shown in Table-2 and Table-3.

Langmuir model was used to fit the equilibrium adsorption data. The model was rearranged and expressed as below. Langmuir equation:

$$
\mathrm{C}_{\mathrm{e}} / \mathrm{Q}_{\mathrm{e}}=\mathrm{C}_{\mathrm{e}} / \mathrm{q}_{\mathrm{m}}+\mathrm{K}_{\mathrm{L}}
$$

where $\mathrm{q}_{\mathrm{m}}$ is the saturated adsorption capacity $(\mathrm{mmol} / \mathrm{g})$, $\mathrm{K}_{\mathrm{L}}$ is the characteristic constants.

The Freundlich and Langmuir adsorption model can give a perfect fitting for all the correlative factors $R^{2}>0.98$. The correlative parameters of Freundlich and Langmuir adsorption isotherm equations for sorbic acid at different temperatures are listed in Table-2 and 3, respectively. Based on the Freundlich and Langmuir theory, coefficient $\mathrm{K}_{\mathrm{f}}$ and $\mathrm{K}_{\mathrm{L}}$ are indication of the adsorbing capacity and $\mathrm{R}^{2}$ denotes the degrees of deviation from isotherm linearity. According to $K_{f}$ and $\mathrm{K}_{\mathrm{L}}$ in Table-2 and 3, the obviously higher adsorbing capacities toward sorbic acid on ZH-01 can be expected. The specific surface area of ZH-01 is larger than that of Amberlite XAD-4, so the adsorbing capacities for sorbic acid on ZH-01 
TABLE-2

REGRESSION EQUATION OF $\log \mathrm{Q}_{\mathrm{e}}$ versus $\log \mathrm{c}_{\mathrm{e}}$ FOR FREUNDLICH ISOTHERMS ON THE ZH-01 AND XAD-4

\begin{tabular}{cccccc}
\hline Adsorbents & $\mathrm{T}(\mathrm{K})$ & \multicolumn{1}{c}{ Regression equation } & $\mathrm{K}_{\mathrm{f}}$ & $\mathrm{n}$ & $\mathrm{R}^{2}$ \\
\hline \multirow{3}{*}{ ZH-01 } & 288 & $\log \mathrm{Q}_{\mathrm{e}}=0.52673 \log \mathrm{C}_{\mathrm{e}}-0.15503$ & 0.6998 & 1.8985 & 0.9891 \\
& 303 & $\log \mathrm{Q}_{\mathrm{e}}=0.52363 \log \mathrm{C}_{\mathrm{e}}-0.18361$ & 0.6552 & 1.7432 & 0.9900 \\
& 318 & $\log \mathrm{Q}_{\mathrm{e}}=0.51519 \log \mathrm{C}_{\mathrm{e}}-0.2704$ & 0.5365 & 1.9410 & 0.9919 \\
\hline \multirow{3}{*}{ XAD-4 } & 288 & $\log \mathrm{Q}_{\mathrm{e}}=0.3754 \log \mathrm{C}_{\mathrm{e}}-0.45304$ & 0.3523 & 1.1849 & 0.9997 \\
& 303 & $\log \mathrm{Q}_{\mathrm{e}}=0.4017 \log \mathrm{C}_{\mathrm{e}}-0.45304$ & 0.3661 & 1.2904 & 0.9982 \\
& 318 & $\log \mathrm{Q}_{\mathrm{e}}=0.4896 \log \mathrm{C}_{\mathrm{e}}-0.49994$ & 0.3163 & 1.2238 & 0.9934 \\
\hline
\end{tabular}

TABLE-3

REGRESSION EQUATION OF $\lg Q_{\mathrm{e}}$ VERSUS $\operatorname{lgc} \mathrm{c}_{\mathrm{e}}$ FOR LANGMUIR ISOTHERMS ON THE ZH-01 AND XAD-4

\begin{tabular}{|c|c|c|c|c|c|}
\hline Adsorbents & $\mathrm{T}(\mathrm{K})$ & Langmuir equation & $\mathrm{q}_{\mathrm{m}}$ & $\mathrm{K}_{\mathrm{L}}$ & $\mathrm{R}^{2}$ \\
\hline \multirow{3}{*}{$\mathrm{ZH}-01$} & 288 & $\mathrm{C}_{\mathrm{e}} / \mathrm{Q}_{\mathrm{e}}=0.81853 \mathrm{C}_{\mathrm{e}}+0.96025$ & 1.1731 & 1.2217 & 0.9961 \\
\hline & 303 & $\mathrm{C}_{\mathrm{e}} / \mathrm{Q}_{\mathrm{e}}=0.59692 \mathrm{C}_{\mathrm{e}}+0.86884$ & 1.4555 & 1.6752 & 0.9993 \\
\hline & 318 & $\mathrm{C}_{\mathrm{e}} / \mathrm{Q}_{\mathrm{e}}=0.63982 \mathrm{C}_{\mathrm{e}}+0.72328$ & 1.1304 & 1.5629 & 0.9993 \\
\hline \multirow{3}{*}{$\mathrm{XAD}-4$} & 288 & $\mathrm{C}_{\mathrm{e}} / \mathrm{Q}_{\mathrm{e}}=0.63036 \mathrm{C}_{\mathrm{e}}+0.61715$ & 0.9790 & 1.5863 & 0.9983 \\
\hline & 303 & $\mathrm{C}_{\mathrm{e}} / \mathrm{Q}_{\mathrm{e}}=0.62464 \mathrm{C}_{\mathrm{e}}+0.46441$ & 0.7466 & 1.6009 & 0.9960 \\
\hline & 318 & $\mathrm{C}_{\mathrm{e}} / \mathrm{Q}_{\mathrm{e}}=0.60167 \mathrm{C}_{\mathrm{e}}+0.37642$ & 0.6256 & 1.6620 & 0.9979 \\
\hline
\end{tabular}

is higher than that on Amberlite XAD-4 within the temperature range $288-318 \mathrm{~K}$ and the saturated adsorption capacity $\left(\mathrm{q}_{\mathrm{m}}\right)$ for sorbic acid on $\mathrm{ZH}-01$ are higher than that on Amberlite XAD-4, which further proved that besides specific surface area, adsorption capacity will be effected by several other factors, including adsorbent polarity, active groups and pore structures, etc. Tables 2 and 3 show the consistency using the above isothermal model that $\mathrm{ZH}-01$ will exhibit its potential at even higher concentrations for column operations.

Isosteric enthalpies for sorbic acid adsorption: The isosteric enthalpies of adsorption were calculated with a derivative van't Hoff equation ${ }^{5,6}$.

$$
\ln \left(1 / \mathrm{C}_{\mathrm{e}}\right)=\ln \left(\mathrm{K}_{0}\right)+(\Delta \mathrm{H} / \mathrm{RT})
$$

where $\Delta \mathrm{H}$ is the isosteric enthalpy change of adsorption reaction $(\mathrm{kJ} / \mathrm{mol})$ when $\mathrm{Q}_{\mathrm{e}}$ is a fixed value, $\mathrm{R}$ is the ideal gas constant and $\mathrm{C}_{\mathrm{e}}$ is equilibrium concentration of solute in $\mathrm{mol} / \mathrm{L}$ at the absolute temperature T. At different temperatures (288 $\mathrm{K}, 303 \mathrm{~K}$ and $318 \mathrm{~K}), \mathrm{C}_{\mathrm{e}}$ is obtained from the Freundlich isotherms when $\mathrm{Q}_{\mathrm{e}}$ equals to $1.0 \mathrm{mmol}, 1.5 \mathrm{mmol}$ and 2.0 mmol. $\Delta \mathrm{H}$ was calculated from the slope of line plotted by $\ln \mathrm{c}_{\mathrm{e}}$ versus $1 / \mathrm{T}$. A summary of the calculated values for enthalpy about $\mathrm{ZH}-01$ adsorbing sorbic acid is listed in Table-4. The $\mathrm{H}$ values imply that the adsorption of sorbic acid by $\mathrm{ZH}-$ 01 is an exothermic process and almost all the values are less than $42 \mathrm{~kJ} / \mathrm{mol}$. It shows a physical adsorption process for sorbic acid on ZH-01 and XAD-4.

Free energies and entropies of adsorption for sorbic acid compound: The free energies of adsorption were calculated with a derivative Gibbs equation ${ }^{7,8}$.

$$
\Delta \mathrm{G}=-\mathrm{nRT}
$$

where $\mathrm{n}$ is a coefficient of Freundlich equation. The entropies change of adsorption was calculated with Gibbs-Helmholtz equation.

$$
\begin{aligned}
\Delta \mathrm{G} & =\Delta \mathrm{H}-\mathrm{T}^{*} \mathrm{~S} \\
\Delta \mathrm{S} & =(\mathrm{H}-\mathrm{G}) / \mathrm{T}
\end{aligned}
$$

A summary of the calculated values for enthalpy, free energy, entropy about ZH-01 and XAD-4 adsorbing sorbic acid are listed in Table-4.

Little change in enthalpy at different $\mathrm{Q}_{\mathrm{e}}$ shows homogeneous nature of the adsorbent surface once again. The absolute heat quantities for ZH-01 are larger than XAD-4's. So, the adsorption abilities of $\mathrm{ZH}-01$ for sorbic acid is stronger than XAD-4's. Due to the adsorbate molecular after adsorption can orderly cover the surface of adsorbent, the disorder and entropy are almost decreasing. Changes in enthalpy, free energy and entropy (always negative) are indicative of an exothermic, spontaneous and disorder process for sorbic acid. All the data on ZH-01 and XAD-4 show that they belong to physical adsorption process.

Adsorption kinetic studies: The influence of contact time on sorbic acid removal by Amberlite XAD-4 and ZH-01 were presented in Figs. 3 and 4. All the adsorbents showed their ability to adsorb sorbic acid with various efficiencies.

The kinetics adsorption data was processed to understand the dynamics of the adsorption process in terms of the rate constant. All the data were fit for the first-order equation form as follows ${ }^{9}$ :

$$
\ln \left[\mathrm{Q}_{\mathrm{e}} /\left(\mathrm{Q}_{\mathrm{e}}-\mathrm{Q}_{\mathrm{t}}\right)\right]=\mathrm{kt} \text { or }-\ln (1-\mathrm{F})=\mathrm{kt}
$$

\begin{tabular}{|c|c|c|c|c|c|c|c|c|}
\hline \multirow{2}{*}{ Adsorbents } & \multirow{2}{*}{$\mathrm{Q}_{\mathrm{e}}(\mathrm{mmol} / \mathrm{g})$} & \multirow{2}{*}{$-\Delta \mathrm{H}(\mathrm{KJ} / \mathrm{mol})$} & \multicolumn{3}{|c|}{$-\Delta \mathrm{G}(\mathrm{KJ} / \mathrm{mol})$} & \multicolumn{3}{|c|}{$-\Delta \mathrm{S}(\mathrm{J} / \mathrm{mol})$} \\
\hline & & & $288 \mathrm{~K}$ & $303 \mathrm{~K}$ & $318 \mathrm{~K}$ & $288 \mathrm{~K}$ & $303 \mathrm{~K}$ & $318 \mathrm{~K}$ \\
\hline \multirow{3}{*}{ ZH-01 } & 1.0 & 13.3 & \multirow{3}{*}{4.55} & \multirow{3}{*}{4.39} & \multirow{3}{*}{5.13} & \multirow{3}{*}{30.36} & \multirow{3}{*}{30.61} & \multirow{3}{*}{27.68} \\
\hline & 1.5 & 13.7 & & & & & & \\
\hline & 2.0 & 13.9 & & & & & & \\
\hline \multirow{3}{*}{ XAD-4 } & 1.0 & 4.36 & \multirow{3}{*}{2.84} & \multirow{3}{*}{3.25} & \multirow{3}{*}{3.24} & \multirow{3}{*}{5.28} & \multirow{3}{*}{5.07} & \multirow{3}{*}{5.84} \\
\hline & 1.5 & 4.79 & & & & & & \\
\hline & 2.0 & 5.09 & & & & & & \\
\hline
\end{tabular}

TABLE-4

ESTIMATED THERMODYNAMIC PARAMETERS OF THE SYSTEMS TESTED 


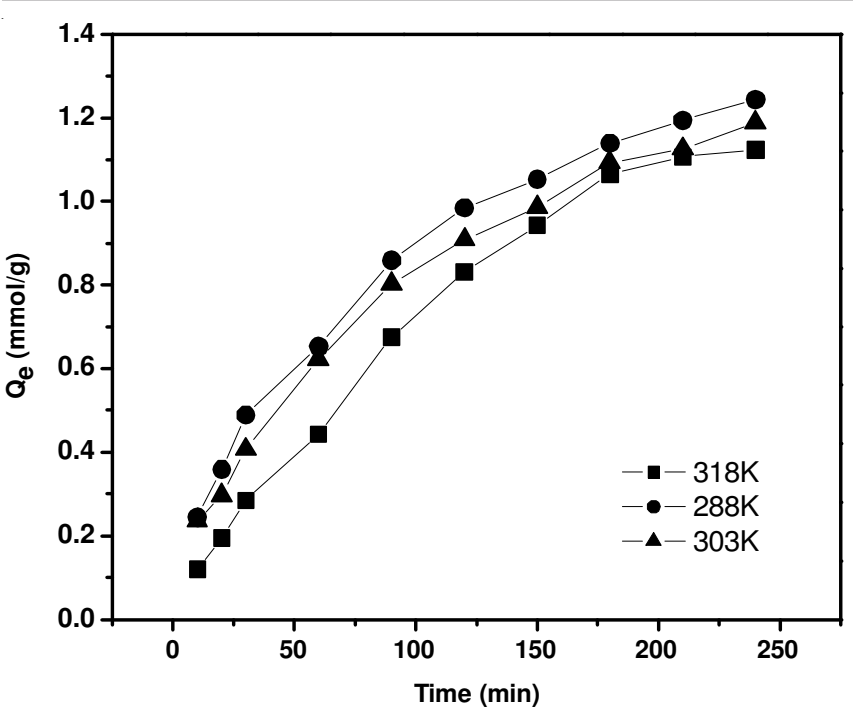

Fig. 3. Influence of contact time on sorbic acid removal by Amberlite $\mathrm{ZH}-01$ at different temperature

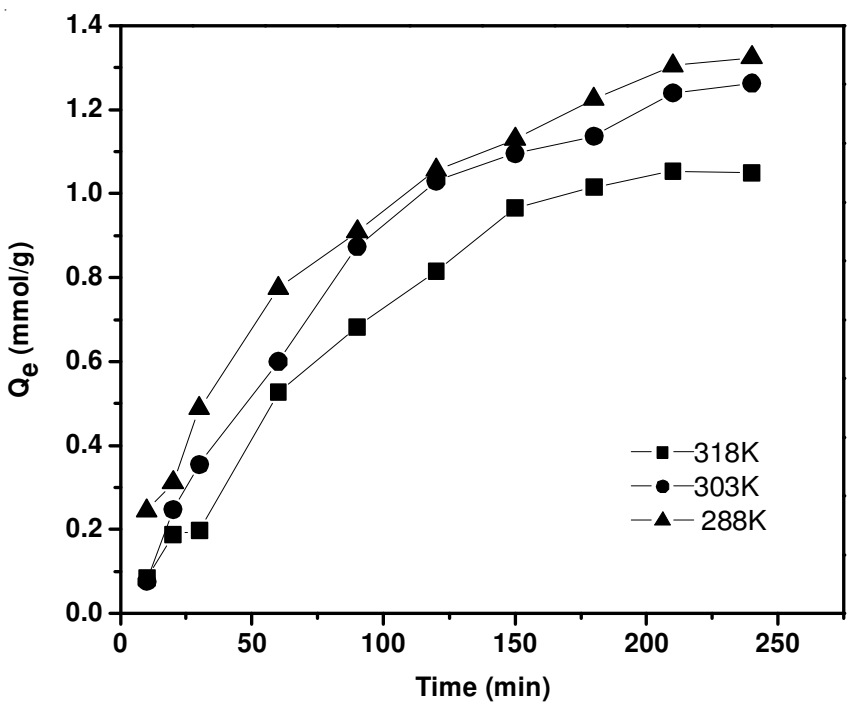

Fig. 4. Influence of contact time on sorbic acid removal by XAD-4 at different temperature

where $\mathrm{Q}_{\mathrm{e}}$ was the equilibrium adsorption capacity ( $\mathrm{mmol} / \mathrm{g}$ ), $\mathrm{Q}_{\mathrm{t}}$ was the adsorption capacity when the contact time $\mathrm{t}$ (mmol/ $\mathrm{g}), \mathrm{F}$ was the fractional attainment of the equilibrium and $\mathrm{k}$ was the overall rate constant $\left(\mathrm{min}^{-1}\right)$, which showed the intraparticle diffusion would not be the rate limiting for the straight line did not pass through the origin. The values of the rate constant $\mathrm{k}$ was calculated from the slope of the plots obtained from $-\ln (1-\mathrm{F}) v s$. the contact of sorbic acid time $\mathrm{t}$ were $0.0156 \mathrm{~min}^{-1}, 0.0239 \mathrm{~min}^{-1}$ and $0.0250 \mathrm{~min}^{-1}$ for $\mathrm{ZH}-01$ at $288 \mathrm{~K}, 303 \mathrm{~K}$ and $318 \mathrm{~K}$, while $0.0123 \mathrm{~min}^{-1}, 0.0117 \mathrm{~min}^{-1}$ and $0.0076 \mathrm{~min}^{-1}$ for XAD-4 at $288 \mathrm{~K}, 303 \mathrm{~K}$ and $318 \mathrm{~K}$, respectively.

\section{Conclusion}

A hypercrosslinked polymeric adsorbent ( $\mathrm{ZH}-01)$ for adsorbing and removing sorbic acid compound from their aqueous solutions has been studied and the equilibrium adsorption capacity for sorbic acid compounds on $\mathrm{ZH}-01$ are markedly higher than that on XAD-4, which can be attributes to its high microporous area and the 2-carboxybenzoyl functional group. The thermodynamics study draws a conclusion for adsorbing sorbic acid compounds on $\mathrm{ZH}-01$ that there is physical adsorption processes. All the isotherm data for the sorbic acid compounds on the XAD-4 and ZH-01 can be satisfactorily fit for the Freundlich and Langmuir equation.

The hypercrosslinked Resins (ZH-01) could effectively remove the sorbic acid from aqueous solution. The new feasible measure for resolve sorbic acid was offered in groundwater micropollution.

\section{ACKNOWLEDGEMENTS}

This work was supported by a grant from the Professor Programs Foundation of Yancheng Teachers University (Grant Code: 13YSYJB0114) and a grant from Innovative Training Project for College Students of Jiangsu province. This project is supported by a grant from the National Natural Science Foundation of China (No. 21307103) and the Natural Science Foundation of the JiangsuHigher Education Institutions of China (Grant No:12KJB610006).The authors expressed sincere gratitude to Bureau of Jiangsu Province, China (Grant Code 13KJD 150005).

\section{REFERENCES}

1. A.M. Li, C. Long, Y. Sun, Q.X. Zhang, F.Q. Liu and J.L. Chen, Sep. Sci. Technol., 37, 3211 (2002).

2. Z.H. Fei, M.F. Xia, L. Wu, J.L. Chen, Y.L. Gu, A.M. Li and Q.X. Zhang, Adsorp. Sci. Technol., 23, 225 (2005).

3. Z.H. Fei, Z.T. Liu, F.Q. Liu, A.M. Li, J.L. Chen and Q.X. Zhang, Acta Chim. Sinica, 65, 1515 (2007).

4. Z.H. Fei, J.L. Chen, J.G. Cai, G.D. Gao, A.M. Li and Q.X. Zhang, Adsorp. Sci. Technol., 22, 439 (2004).

5. W.H. Tao, A.M. Li, C. Long, Z.C. Fan and W.W. Wang, J. Hazard. Mater., 193, 149 (2011).

6. W.H. Tao, A.M. Li, C. Long, H.M. Qian, D.J. Xu and J. Chen, J. Hazard. Mater., 175, 111 (2010).

7. J.P. Wang and Z.H. Fei, Chinese J. Polym. Sci., 24, 545 (2006).

8. J.P. Wang, S.H. Tang, Z.H. Fei, J. Chen and Y. F. Sun, Chinese J. Polym. Sci., 28, 241 (2010).

9. Z.H. Fei, J.L. Chen, J.G. Cai, Y.P. Qiu, A.M. Li and Q.X. Zhang, Chinese J. Polym. Sci., 22, 531 (2004). 